\title{
EDITORIAL
}

\section{Migraine-inspired art}

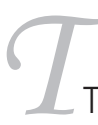

The experience with recurrent migraine attacks, particularly those with aura, were used as artistic inspiration by some famous people such as Hildegard of Bingen, Salvador Dali, Marina Abramovic, Giorgio de Chirico, Yayoi Kusama, Sarah Raphael, among others. In the present issue Ermelinda Ferreira comments the work of the German nun Hildegard von Bingen, author of two of the first medical compendiums of the history of mankind and migraine sufferer. Other interesting and informative articles commenting disease progression to chronic migraine, cerebrovascular reactivity in migraineurs, use of a diagram of the skull to report localization of pain, migraine and academic performance, and allodynia in cluster headache were included in this issue.

Marcelo M. Valença \& Fernando Kowacs 